\title{
Flutuação populacional de insetos-praga na cultura da soja no Estado de Roraima
}

\author{
Population fluctuation of insect pests in soybean crop in Roraima State
}

\author{
Alberto Luiz Marsaro Júnior ${ }^{[a]}$, Paulo Roberto Valle da Silva Pereira ${ }^{[\mathrm{b}]}$, \\ Wagner Ribeiro da Silva ${ }^{[c]}$, Sônia Cristina Pereira Griffel ${ }^{[\mathrm{d}]}$ \\ [a] Entomologista, Doutor, Embrapa Roraima, Boa Vista, RR - Brasil, e-mail: alberto@cpafrr.embrapa.br \\ [b] Entomologista, Doutor, Embrapa Trigo, Passo Fundo, RS - Brasil, e-mail: paulo@cnpt.embrapa.br \\ [c] Acadêmico de Biologia das Faculdades Cathedral, Boa Vista, RR - Brasil, e-mail: wagnerspad@bol.com.br \\ [d] Acadêmica de Biologia das Faculdades Cathedral, Boa Vista, RR - Brasil, e-mail: sonigriffell@hotmail.com
}

\section{Resumo}

Este trabalho teve por objetivo avaliar a flutuação populacional das principais pragas da cultura da soja no Estado de Roraima. O estudo foi realizado nos campos experimentais da Embrapa Roraima, Água Boa e Monte Cristo, numa área de $600 \mathrm{~m}^{2}$, em cada campo, durante os meses de junho (estádio V2) a setembro (estádio R8), na cultivar de soja Tracajá, no ano de 2006. Durante o estudo, as áreas não receberam nenhuma aplicação de inseticida e os insetos foram coletados semanalmente, utilizando-se o pano de batida, num total de dez batidas de pano por semana. A partir dos dados coletados, foram construídos gráficos com as flutuações populacionais das principais pragas levantadas ao longo do ciclo da cultura da soja. As lagartas desfolhadoras $A$. gemmatalis e $P$. includens apresentaram seus picos populacionais na fase vegetativa da cultura, mas em baixa densidade populacional e sempre abaixo do nível de controle. Os percevejos fitófagos E. heros, $P$. guildinii e N. viridula apresentaram seus picos populacionais na fase reprodutiva da cultura, mas somente em uma das áreas experimentais avaliadas a densidade populacional atingiu o nível de controle, considerando o destino da lavoura para produção de grãos. O coleóptero desfolhador C. arcuata apresentou os picos populacionais na fase vegetativa, nas duas áreas experimentais avaliadas.

Palavras-chave: Lagartas da soja. Percevejos. Cerotoma arcuata.

\section{Abstract}

The objective of this work was to evaluate the population fluctuation of main insect pests on soybean crop in Roraima State. The study was conducted in 2006 in two areas at the experimental fields of Água Boa and Monte Cristo, both belonging to Embrapa Roraima. Each field had an area of 600 $\mathrm{m}^{2}$, in Tracajá cultivar and sampling procedures were made during the months of June (V2 stage) 
and September (R8 stage). There were not insecticidal pulverizations during the study; insects were collected weekly, using a shake cloth, in a total of ten samples per week. Population fluctuation graphics of the main pests during the development of soybean crop were built using the information obtained in the field. The caterpillars A. gemmatalis and P. includens presented a populational peak at the vegetative stage of the crop, but in low populational densities and below the control level. The stinkbugs E. heros, P. guildinii and N. viridula reached their populational peaks in the reproductive stage of the crop, but only in one of the experimental areas the populational density reached the control level, considering the use of the crop for grain production. The defoliator beetle Cerotoma arcuata presented the population peak at the vegetative stage in both studied areas.

\section{Keywords: Soybean caterpillars. Stinkbugs. Cerotoma arcuata.}

\section{Introdução}

A soja é uma das principais leguminosas de importância econômica e social para o Estado de Roraima. Na safra de 2006 foram plantados 6.900 ha, totalizando 19.458 toneladas de grãos, com uma produtividade média de $2.820 \mathrm{~kg} / \mathrm{ha}$ (SMIDERLE, 2006). Essa média poderia ser maior, porém, a presença de insetos-praga, durante todo o ciclo da cultura, contribui para a redução da produtividade.

Os principais insetos-praga da cultura da soja, em Roraima, são as lagartas desfolhadoras Anticarsia gemmatalis, Psendoplusia includens e Omiodes indicata (PEREIRA et al., 2004a), os percevejos fitófagos Nezara viridula, Piezodorus guildinii, Euschistus heros e Edessa meditabunda (PEREIRA et al., 2004b; MARSARO Jr. et al., 2007), a mosca-branca Bemisia tabaci (LIMA et al., 2006) e os coleópteros desfolhadores Diabrotica speciosa e Cerotoma arcuata (MARSARO Jr. et al., 2007).

Os danos das lagartas, pelo consumo de área foliar, acarretam redução da área fotossintética das plantas, comprometendo, consequentemente, a produção, principalmente se as desfolhas ocorreram durante os estádios reprodutivos da cultura. O consumo da área foliar varia de acordo com a espécie. Uma larva de $A$. gemmatalis consome em média $90 \mathrm{~cm}^{2}$; uma de $P$. includens, $120 \mathrm{~cm}^{2}$; e uma de $O$. indicata, $30 \mathrm{~cm}^{2}$ (NAKANO et al., 1981; GALLO et al., 2002).

Os principais danos dos percevejos na cultura da soja, segundo Gazzoni e Yorinori (1995), são: redução da produtividade, por causa do aborto de vagens e/ou grãos, além de redução de tamanho e peso; redução do poder germinativo e do vigor da semente e alterações bioquímicas nas frações proteicas e lipídicas do grão; retenção foliar da soja, ou seja, embora os grãos já estejam secos e prontos para a colheita, a planta não se desfaz de suas folhas ou permanece com os ramos e os caules verdes. Quando a lavoura enfrenta esse distúrbio, a colheita não pode ser efetuada em condições ideais, o que causa perda adicional da produção e da qualidade do grão.

Gallo et al. (2002) acrescentam ainda que, no caso do ataque dos percevejos às vagens, os prejuízos podem chegar a 30\%, pois com a sucção da seiva as vagens ficam marrons e "chochas". Além disso, os percevejos podem causar manchas nos grãos já formados, as quais são conhecidas por "mancha de levedura" ou "mancha fermento", causadas por fungos.

Os adultos dos coleópteros desfolhadores, D. speciosa e C. arcuata, atacam, de preferência, as folhas mais tenras, e nestas fazem um grande número de pequenos orifícios. Quando o ataque é muito intenso, podem ocorrer atrasos no desenvolvimento das plantas (GALLO et al., 2002).

Para reduzir os danos causados por esses insetos, medidas de controle normalmente são adotadas. Não se recomenda, porém, que o controle das pragas seja realizado sem um critério técnico. Orienta-se que essa tomada de decisão baseie-se no monitoramento populacional das pragas ao longo do ciclo da cultura. Os níveis de ação de controle para as principais pragas da soja dependem do tamanho e da densidade do inseto, do nível do dano, da fase de desenvolvimento da cultura e do destino final da produção (grãos ou sementes) (EMBRAPA, 2006). 
Diversos levantamentos de insetos-praga da soja, ao longo do ciclo da cultura, já foram realizados no Brasil (MORAES et al., 1991; HEINECK-LEONEL; CORSEUIL, 1997; DIDONET et al., 1998; DIDONET et al., 2003; BELORTE et al., 2003).

São raros, no entanto, levantamentos de insetos-praga na cultura da soja na região norte do Brasil e, por isso, este trabalho teve por objetivo avaliar a flutuação populacional das principais pragas da cultura da soja no Estado de Roraima.

\section{Material e métodos}

Este trabalho foi realizado nos campos experimentais da Embrapa Roraima, Água Boa e Monte Cristo, numa área de $600 \mathrm{~m}^{2}$, em cada campo, durante os meses de junho (estádio V2) a setembro (estádio R8), na cultivar de soja Tracajá, no ano de 2006. Durante o estudo as áreas não receberam nenhuma aplicação de inseticida, e os insetos foram coletados semanalmente, utilizando-se o pano de batida, num total de dez batidas de pano por semana, à semelhança de Moraes et al. (1991).

No caso das lagartas, o pano de batida foi colocado entre duas fileiras de soja. Nessas fileiras, as plantas foram sacudidas sobre a área do pano, para posterior contagem das lagartas (maiores que $1,5 \mathrm{~cm}$ de comprimento). No caso dos percevejos, contabilizados os que apresentaram mais de 0,5 de comprimento, o pano foi colocado de tal forma a amostrar as pragas em apenas uma fileira (EMBRAPA, 2006). A partir dos dados coletados, foram construídos gráficos com as flutuações populacionais das principais pragas levantadas ao longo do ciclo da cultura da soja.

\section{Resultados e discussão}

Podemos observar que as lagartas desfolhadoras $A$. gemmatalis e $P$. includens apresentaram seus picos populacionais na fase vegetativa da cultura, nas duas áreas avaliadas (Figuras 1 e 2). Esses resultados diferiram dos observados no Estado do Rio Grande do Sul por Moraes et al. (1991), que constataram que os picos populacionais das lagartas desfolhadoras ocorreram na fase reprodutiva da cultura.

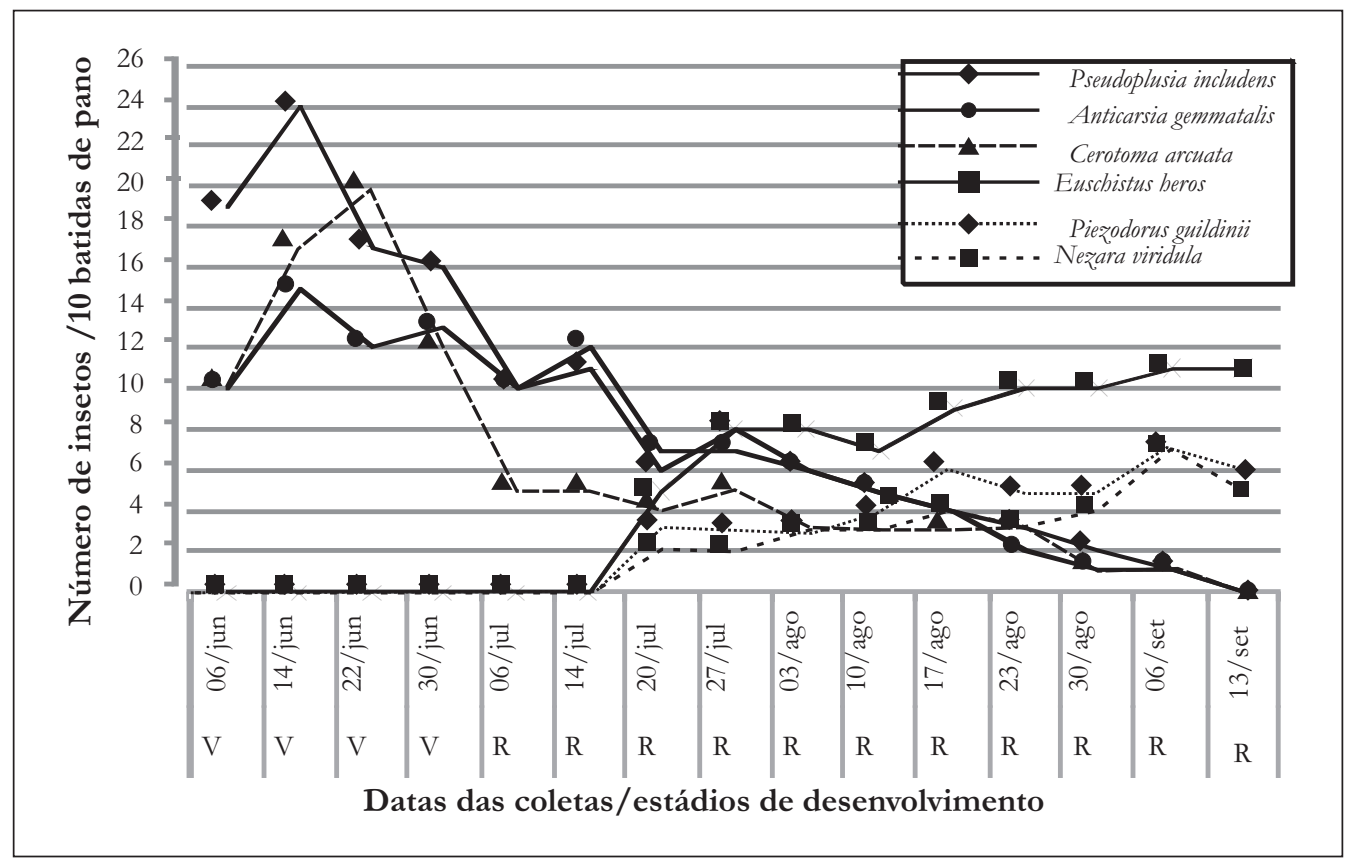

Figura 1 - Flutuação populacional de insetos-praga na cultura da soja, cultivar Tracajá, Campo Experimental Água Boa, Boa Vista/RR, 2006 


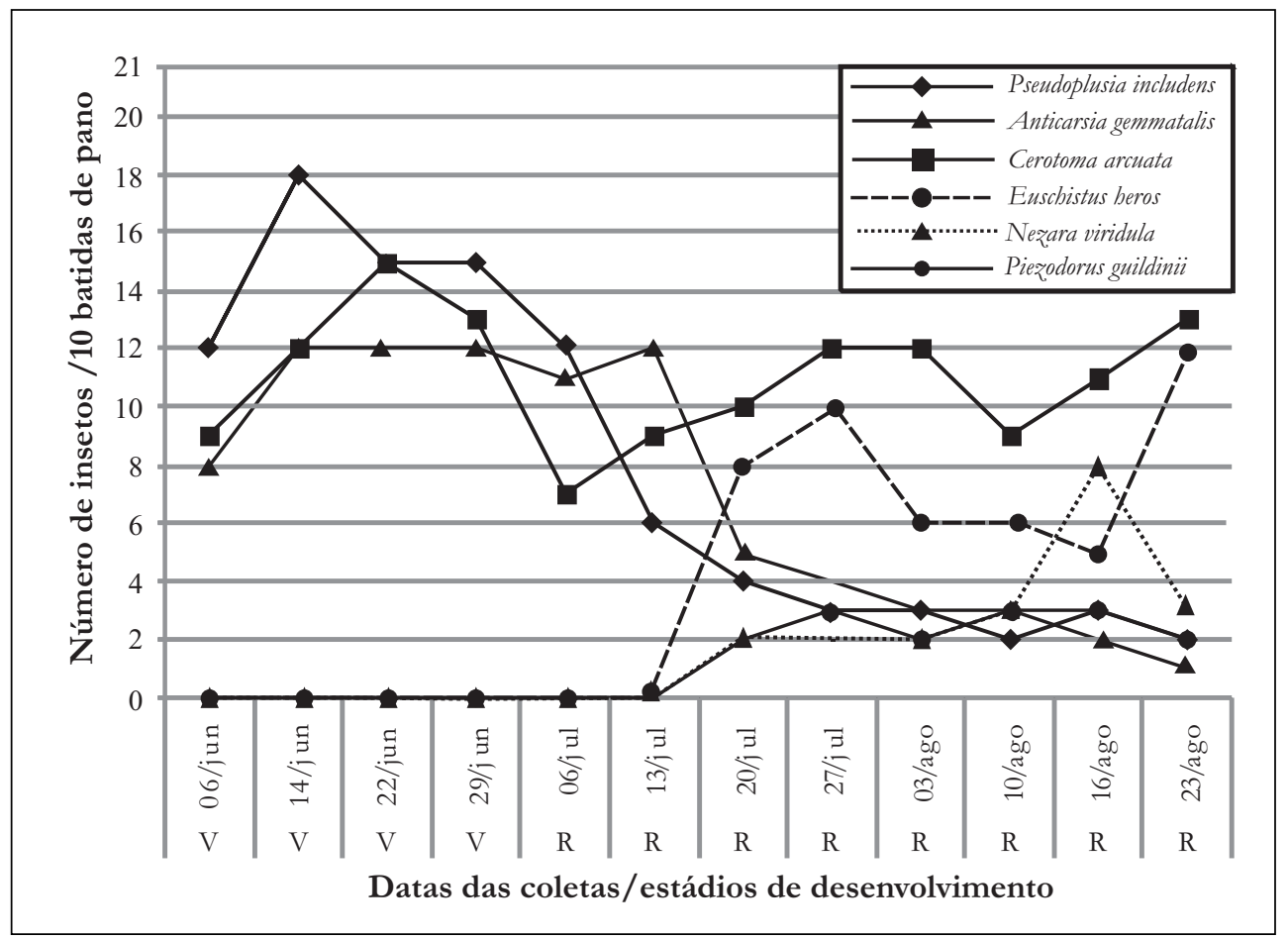

Figura 2 - Flutuação populacional de insetos-praga na cultura da soja, cultivar Tracajá, Campo Experimental Monte Cristo, Boa Vista/RR, 2006

Podemos observar também nas Figuras 1 e 2 que, de maneira geral, a espécie P. includens predominou sobre a $A$. gemmatalis, visto que apresentou o maior número de indivíduos coletados. Esses resultados também diferiram dos observados por Moraes et al. (1991), que constataram que quando as lagartas desfolhadoras Plusiinae ocorreram simultaneamente com as A. gemmatalis, as últimas sempre predominaram. Essas diferenças regionais com relação às lagartas predominantes na cultura da soja, bem como às fases de ocorrência dos picos populacionais, demonstram que não podemos fazer generalizações e que em cada região, com suas diferentes características, pode apresentar variações nas interações que ocorrem na entomofauna associada à cultura.

Considerando os valores máximos de espécimes coletados das lagartas $P$. includens e A. gemmatalis, 24 e 15 respectivamente, registrados no Campo Experimental Água Boa, em 24 junho (Figura 1), constata-se, ainda, que esses valores ficaram abaixo do nível de controle estabelecido para as lagartas desfolhadoras, que é de 40 lagartas/2 m (EMBRAPA, 2006). Nos estudos realizados por Didonet et al. (1998) e Didonet et al. (2003), os autores também constataram que os picos populacionais das lagartas desfolhadoras não atingiram o nível de controle. Visto que não houve aplicação de inseticidas nas áreas experimentais do presente estudo, é provável que a ação dos inimigos naturais tenha contribuído para a manutenção dos baixos índices populacionais dessas lagartas desfolhadoras.

Podemos observar que os percevejos fitófagos E. heros, P. guildinii e N. viridula apresentaram seus picos populacionais na fase reprodutiva da cultura, nas duas áreas avaliadas (Figuras 1 e 2). Esses resultados concordam com os encontrados por Didonet et al. (1998) e Didonet et al. (2003).

Podemos observar também nessas figuras que, de maneira geral, a espécie E. heros predominou sobre as espécies $P$. guildinii e $N$. viridula, visto que apresentou o maior número de indivíduos coletados. Esses resultados diferiram dos encontrados por Didonet et al. (1998) e Didonet et al. (2003), que constataram que a espécie predominante foi $P$. guildinii. Essa diferença com relação à predominância de uma espécie de percevejo sobre outra é bastante comum, uma vez que depende da região onde o estudo foi desenvolvido e das cultivares avaliadas. Messenger (1959), citado por Belorte et al. (2003), menciona que as variações das populações de percevejos nas diferentes regiões produtoras de soja do país estão relacionadas ao clima, responsável em grande parte pela abundância e distribuição dos insetos. 
A soma dos valores máximos de espécimes coletados dos percevejos E. heros, P. guildinii e $N$. viridula, registrados no campo experimental Água Boa, entre 6 e 13 de setembro, foi de 25 e 22 percevejos, respectivamente (Figura 1). Portanto, nessas datas registrou-se uma média de 2,5 e 2,2 percevejos por batida de pano, respectivamente. Visto que o nível de controle estabelecido para uma lavoura de soja destinada à produção de grãos é de dois percevejos/m (EMBRAPA, 2006), conclui-se que nessas datas a população dos percevejos superou o nível de controle e, caso fosse uma lavoura comercial, medidas de controle deveriam ser adotadas. Nos estudos realizados por Didonet et al. (2003), os autores verificaram que os percevejos, na fase reprodutiva da cultura da soja, também atingiram o nível de controle.

Podemos observar que $C$. arcuata apresentou picos populacionais na fase vegetativa, nos dois campos experimentais avaliados, no dia 22 de junho (Figuras 1 e 2).

Nessas figuras podemos observar que C. arcuata foi registrado durante todo o ciclo da cultura e também apresentou um pico populacional na fase reprodutiva, dia 23 de agosto, no campo experimental do Monte Cristo (Figura 2). Resultados semelhantes também foram observados por Heineck-Leonel e Corseuil (1997), Didonet et al. (1998) e Didonet et al. (2003). Segundo Sosa-Gomez et al. (1993), citados por Didonet et al. (2003), os coleópteros desfolhadores vêm crescendo em importância em lavouras de soja plantadas em áreas de cerrado.

Ainda não existe nível de controle estabelecido para coleópteros desfolhadores na cultura da soja, mas, visto que esses insetos estão frequentemente associados à essa cultura, seria importante o desenvolvimento de estudos que quantificassem o dano desses coleópteros para que se possa estabelecer níveis de controle para o manejo mais eficiente e mais sustentável dessas pragas.

O monitoramento das populações dos insetos-praga ao longo do ciclo da cultura é fundamental para auxiliar na tomada de decisão do controle. A adoção dessa prática contribui para a redução do uso de inseticidas, do uso de combustíveis fósseis e das contaminações no homem, nos alimentos e no meio ambiente.

\section{Conclusões}

- As lagartas desfolhadoras $A$. gemmatalis e $P$. includens apresentaram seus picos populacionais na fase vegetativa da cultura, mas em baixa densidade populacional e sempre abaixo do nível de controle; - Os percevejos fitófagos E. heros, P. guildinii e N. viridula apresentaram seus picos populacionais na fase reprodutiva da cultura, mas somente em uma das áreas experimentais avaliadas a densidade populacional atingiu o nível de controle, considerando o destino da lavoura para produção de grãos; - O coleóptero desfolhador C. arcuata apresentou os picos populacionais na fase vegetativa, nas duas áreas experimentais avaliadas.

\section{Referências}

BELORTE, L. C. C.; RAMIRO, Z. A.; FARIA, A. M. Levantamento de percevejos pentatomídeos em cinco cultivares de soja [Glycine max (L.) Merrill, 1917] no município de Araçatuba, SP. Arquivos do Instituto Biológico, v. 70, n. 4, p. 447-451, 2003.

DIDONET, J. et al. Flutuação populacional de pragas e seus inimigos naturais em soja no projeto Rio Formoso Formoso do Araguaia, TO, Brasil. Acta Amazônica, n. 28, v. 1, p. 67-74, 1998.

DIDONET, J. et al. Abundância de pragas e inimigos naturais em soja na região de Gurupi, Brasil. Manejo Integrado de Plagas y Agroecología, n. 69, p. 50-57, 2003.

EMPRESA BRASILEIRA DE PESQUISA AGROPECUÁRIA - EMBRAPA. Manejo de insetos-praga. In: EMPRESA BRASILEIRA DE PESQUISA AGROPECUÁRIA - EMBRAPA. Tecnologias de produção de soja - Região Central do Brasil - 2007. Londrina: Embrapa Soja; Embrapa Cerrados; Embrapa Agropecuária Oeste, 2006. p. 145-167. (Sistemas de produção/Embrapa Soja, n. 11). 
GALLO, D. et. al. Entomologia agrícola. Piracicaba: FEALQ, 2002.

GAZZONI, D. L.; YORINORI, J. T. Manual de identificação de pragas e doenças da soja. Brasília: EMBRAPA - SPI, 1995.

HEINECK-LEONEL, M. A.; CORSEUIL, E. Flutuação populacional de Cerotoma arcuata tingomariana (Bechyné) (Coleoptera: Chrysomelidae) em soja. Anais da Sociedade Entomológica do Brasil, v. 26, n. 1, p. 183-185, 1997.

LIMA, A. C. S. et al. Incidência de mosca-branca Bemisia tabaci (Hemiptera: Aleyrodidae) em cultivares de soja em Roraima. In: CONGRESSO BRASILEIRO DE ENTOMOLOGIA, 21., 2006, Recife. Resumos... Recife: SEB, 2006. CD-ROM.

MARSARO Jr, A. L.; PAIVA, W. R. S. C.; BARRETO, H. C. S. Monitoramento de insetos-praga na cultura da soja em Roraima. Comunicado Técnico, n. 18, p. 9, 2007.

MESSENGER, P. S. Bioclimatic studies with insects. Annual Review of Entomology, v. 4, p. 183-206, 1959.

MORAES, R. R.; LOECK, A. E.; BELARMINO, L. C. Flutuação populacional de Plusïnae e Anticarsia gemmatalis Hubner, 1818 (Lepidoptera: Noctuidae) em soja no Rio Grande do Sul. Pesquisa Agropecuária Brasileira, n. 26, n. 1, p. 51-56, 1991.

NAKANO, O.; SILVEIRA NETO, S.; ZUCCHI, R. A. Entomologia econômica. São Paulo: Livroceres, 1981.

PEREIRA, P. R. V. S. et al. Lagartas desfolhadoras (Insecta: Lepidoptera) da soja cultivada em Roraima: identificação, biologia, danos e práticas de controle. Comunicado Técnico, n. 12, p. 12, 2004a.

. Percevejos (Hemiptera: Pentatomidae) da soja cultivada em Roraima: identificação, biologia, danos e práticas de controle. Comunicado Técnico, n. 20, p. 9, 2004b.

SMIDERLE, O. J. Roraima: evolução da cultura da soja. In: REUNIÃO DE PESQUISA DE SOJA DA REGIÃO CENTRAL DO BRASIL, 28., 2006, Uberaba, Ata... Londrina: Embrapa Soja, 2006. p. 70-72. (Embrapa Soja. Documentos, 275).

SOSA-GOMEZ, D. R. et al. Pragas da soja e seu controle. In: ARANTES, N. E.; SOUZA, P. I. M. (Ed). Cultura da soja nos cerrados. Piracicaba: Potafos, 1993. p. 299-331.

Recebido: 27/07/2009

Received: $07 / 27 / 2009$

Aprovado: 22/12/2009

Approved: 12/22/2009 